\title{
IR-testing of thermal performance of concrete slab buildings
}

\author{
by Imre BENKÖ \\ Budapest University of Technology and Economics (BME), Faculty of Mechanical Engineering, \\ Department of Energy (DoE), H-1521 Budapest, Müegyetem rkp. 7./D.208. Hungary, DoE Tel/Fax: \\ +361-463-3273, e-mail: benko@eta.enrg.bme.hu
}

\begin{abstract}
The applicability (advantages and limitations) of IR-images and their scientific value are determined in the technical practice by the type of the technical phenomenon investigated; consideration of rules of IR-optics during the IR-image-taking; proper selection of ambient parameters. Under optimum conditions, the IR-image will contain all important information on the thermal character of the temperature field of the examined object or phenomenon. As a consequence, the evaluation of IRimages, the thermophysical characteristics and interpretation will contribute to the scientific value of IR-images. In the actual practice of IR-image analysis one may choose between three general methods, however their relative advantages and disadvantages must be decided in the light of the tests being done. The first is the traditional phenomenological analysis [1]. Two new methods serve for mathematical evaluation of temperature fields: the histographic analysis, i.e. the application of the distribution curve of temperature histogram for process monitoring [2], and the mathematical filtering of IR-images to reveal the sites of highest temperature or of the largest temperature alterations [5],[6]. This paper presents these practical methods of IR-image analysis in the field of building engineering [4].
\end{abstract}

\section{Introduction}

Histographic processing is the usual mode of processing experimentally and otherwise obtained sets of data, but it may be considered as an efficient way for describing temperature fields, too. Thereby there is still little experience available for such applications and for the proper evaluation of all histogram characteristics [1],[2].

In histograms which represent temperature fields of digital IR-images, the percentages of pixel numbers with the given temperature are plotted against temperatures occurring within the fields (Fig.1). Temperatures occurring in the selected area may be displayed both graphically and digitally, and the obtained data lend themselves for further computations [5]. In our practice satisfactory results were obtained when the temperature varied by tenths of degrees within the range[3].

Among essential values characteristic of the histograms, the following are pointed out: the highest (max), the lowest ( $\min )$ and the average (avg) temperature in the defined area; mediane (med), standard deviation (Sdev) and skewness (Skew)(Table 2); number of pixels in the examined area ( $\mathrm{Ncal}$ ) and the maximum value on the ordinate of the histogram (Fmax).

The distribution curve (D) of histogram is the integral of the histogram (Figure 2). By this approach sensitive measurements could be made through the value of $D$ for comparison of different cases (note: mediane is at $D=0.5$ ).

\section{Quantitative factors}

In addition to the common histographic parameters, two thermal factors were defined calculating through the histographic data. They represent the inequality and as well as the heat increasing of the temperature field of the concrete slab, bringing about the slab-joints. 
We can observe two principal types of the different thermal faults on concrete slabs. The first one is the systematic fault on the edges (slab-joints) of a minor area of the entire slab (Fig. 3 and 4). The second one is the casual fault in the middle part on the minor area of the panel (Fig. 5). The efficiency ratio between the heat losses of the "perfect" and the "real" panels is the energy saving factor (ES), showing the energy saving possibility in some cases of correction of the thermal bridges of wall-joints. Inequality factor (IE) is the parameter of casual faults, inside the panel.

\subsection{Inequality factor}

The inequality (ie) factor (IE) was defined as the ration of the maximum temperature difference on the panel $\Delta \mathrm{t}_{\mathrm{ie}}=\mathrm{t}_{\max }-\mathrm{t}_{\min }$ and the average temperature difference between the panel (avg) and the environment (env): $\Delta \mathrm{t}_{\mathrm{env}}=\mathrm{t}_{\mathrm{avg}}-\mathrm{t}_{\mathrm{env}}$. Thus, we have

$$
I E=\Delta t_{i e} / \Delta t_{e n v}
$$

The domain of definition of the IE factor is between $0 \ldots 2$. If $\Delta \mathrm{t}_{\mathrm{ie}}=\Delta \mathrm{t}_{\mathrm{env}}$ then IE=1 and IE=2 if $\Delta \mathrm{t}_{\mathrm{ie}}=2 \Delta \mathrm{t}_{\mathrm{env}}$ (see Table 1 ).

\subsection{Energy saving factor}

In the majority of cases, the average temperature of wall-joint (j) is higher than in the interior part of the slab (sl). So the energy saving factor (ES) was defined as the ratio of heat losses of the wall-joint $\left(\dot{Q}_{\mathrm{j}}\right)$ surface $\left(\mathrm{A}_{\mathrm{j}}\right)$ and that of the "perfect" $\left(\dot{Q}_{\mathrm{sl}}\right)$ slab $\left(\mathrm{A}_{\mathrm{sl}}\right.$, sl-slab). Analogously to the Equ. 5, we may give the following definition of the ES factor:

$$
E S=\frac{\dot{Q}_{j}}{\dot{Q}_{s l}}=\frac{\alpha_{j} A_{j}\left(t_{j}-t_{e n v}\right)}{\alpha_{s l} A_{s l}\left(t_{s l}-t_{e n v}\right)} .
$$

Substituting an approach of $\alpha_{j}=\alpha_{s l}$ in Equ.2 and denoting the area factor by $a=A_{j} / A_{s l}$ we finally have:

$$
E S=a \frac{\left(t_{j}-t_{\text {env }}\right)}{\left(t_{s l}-t_{\text {env }}\right)}
$$

If $\mathrm{t}_{\mathrm{j}}=\mathrm{t}_{\max }$ and $\mathrm{t}_{\mathrm{s}}=\mathrm{t}_{\min }$ then we shall have

$$
E S=a \frac{\left(t_{\max }-t_{e n v}\right)}{\left(t_{\min }-t_{e n v}\right)}
$$

We present the calculated IE and ES factors for Fig.3, 4 and 5 in Table 2.

\section{Thermal engineering applications}

For the calculation of heat loss of a concrete slab (panel) surface, in steady state conditions we have to know the wall temperature with appropriate accuracy. Connection between the average wall temperature $\left(\mathrm{t}_{\text {avg }}\right)$ and heat loss $(\dot{Q})$ is given by the following 
Equation:

$$
\dot{Q}=\sum_{i=1}^{n} A_{i} \alpha_{i}\left(t_{\text {avg }}-t_{\text {env }}\right)
$$

Here $A_{i}$ is a selected minor area $(i=1 \ldots n)$ of the measured surface where $\alpha_{i}$ the coefficient of heat transfer and emissivities are constant, $t_{\text {env }}$ is the temperature of environment. So the values of temperature distribution in the selected area very important for the determination of heat loss and other practical calculations (Table 1).

\subsection{Wall and floor heating}

Determination of heat transfer by panels with internal heating at a due accuracy requires the knowledge of the mean wall temperature (Equation 1). The obtained thermogram and histograms assist reliable thermal sizing. One horizontal (a) and vertical (b) profilthermogram set across the wall-sections, which is heated by an internal pipe coil, can be presented in a figure [2] (Table 2).

\subsection{Checking a building envelope}

Insulation quality control of the pre-fabricated panel building is an important practical task. The spots of thermal bridges may be pointed out in IR-images. For the calculations of local heat losses in the different areas of the building envelope can be analysed. IR-thermogram and histogram below the windows are presented in figures [4].

The first method of IR-image analysis is the traditional phenomenological analysis, e.g.

determining the temperature at specified points of the surface under test (e.g. the centre point of the hair cross) (Fig. 3.),

- a comparison between temperature distributions along the horizontal, vertical or optional lines(Fig. 4.),

- relief representation of the temperature field.

Histograms of a selected area around, below and between the windows can be seen on Fig.1. Fig.4 shows the spots of the thermal bridges. For the comparison of different areas of the building envelope the distribution of histograms around, below and between a window is presented as a comparative results (Fig. 2). The data of the referred IR-histograms are collected in Table 2. Efficiency parameters, e.g. the efficiency ratio between the "perfect" and the "real" panels gives us a quantitative indication regarding the thermal performance of the panels (see Section 3. and Tables 1. and 2.).

\section{Conclusion}

Applications of quantitative infrared thermogrammetry by histograms and distribution of histograms in the representation of temperature fields give direct result in heat loss calculations (IE and ES factors), checking thermal insulation efficiency and defects.

\section{References}

[1] BENKÖ, I., "Applications of infrared thermogrammetry in thermal engineering", QIRT 92 - Eurotherm Series 27, Paris, 1992, p 343-349

[2] BENKÖ, I., "Histographic analysis of infrared thermograms in the field of engineering", Workshop '93 on Advanced Infrared Technology and Applications. IROE-CNR, Capri, 1993, p 33 
[3] BENKÖ, I., "Relationship between thermal engineering and thermogrammetry", Abstracts of $8^{\text {th }}$ International Conference on Thermal Engineering and Thermogrammetry. Budapest, 2-4 June, 1993, p 5-12

[4] BENKÖ, I., "Thermal detection of buildings and environment by INFRAMETRICS devices", Energy and the Environment. Proceedings of the Second Trabzon International Energy and Environment Symposium. Edited by I. Dincer and T.Ayhan, Begell House, Inc.

New York, 1999, p 205-208

[5] BENKÖ, I.,"Infra-red image filtering as a tool of temperature-field analysis", Proceedings of TEMPMEKO '99. Edited by J.F. Dubbeldam and M.J. de Groot. NMi Van Swinden Laboratorium, Delft, Vol.2, 1999, p 657-662

[6] BENKÖ, I.,"Analysis of infrared thermograms through mathematical filtering", Gépészet 2000, Proceedings of Second Conference on Mechanical Engineering, edited by K.Molnár, Gy. Ziaja, G. Vörös, Springer Medical Publishers, Budapest, 2000, Vol.2, p 350355

Table 1: Data of the simple histographic analysis

\begin{tabular}{|c|c|c|c|c|c|c|c|}
\hline \multirow{2}{*}{$\begin{array}{c}\text { End-wall } \\
\text { No. }\end{array}$} & \multirow{2}{*}{$\begin{array}{l}\text { Floor } \\
\text { No. }\end{array}$} & \multicolumn{3}{|c|}{$\begin{array}{l}\text { Values of temperature } \\
\text { distribution, }{ }^{\circ} \mathrm{C}\end{array}$} & \multicolumn{2}{|c|}{$\begin{array}{l}\text { Quantitative } \\
\text { factors }\end{array}$} & \multirow{2}{*}{$\begin{array}{l}\text { Spot, } \\
{ }^{\circ} \mathrm{C}\end{array}$} \\
\hline & & $\min$. & avg. & $\max$. & IE & ES & \\
\hline \multirow{4}{*}{$\begin{array}{l}1 . \\
\text { East-side } \\
\mathrm{t}_{\text {env }}=4^{\circ} \mathrm{C} \\
\mathrm{a}=0.2\end{array}$} & 10 & 7.7 & 11 & 15.5 & 0.97 & 0.37 & \\
\hline & 8. & 8.7 & 12 & 15.9 & 0.9 & 0.31 & \\
\hline & 7. & 8.0 & 11.9 & 15.9 & 1.0 & 0.39 & $15.2 / 9.9$ \\
\hline & 10.-7. & 7.3 & 11.6 & 15.9 & 1.13 & 0.23 & \\
\hline \multirow{4}{*}{$\begin{array}{l}2 . \\
\text { West-side } \\
t_{\text {env }}=4^{\circ} \mathrm{C} \\
a=0.1\end{array}$} & 10. & 5.2 & 9.7 & 13.7 & 1.49 & 0.71 & \\
\hline & 8. & 6.6 & 10.5 & 14.7 & 1.25 & 0.31 & \\
\hline & 7. & 6.3 & 10.2 & 14.2 & 1.27 & 0.34 & $12.7 / 9.9$ \\
\hline & 10.-7. & 5.2 & 10.2 & 14.7 & 1.53 & 0.79 & \\
\hline \multirow{4}{*}{$\begin{array}{l}3 . \\
a=0.1 \\
t_{\text {env }}=0{ }^{\circ} \mathrm{C}\end{array}$} & 4. & 0.7 & 2.6 & 4.9 & 1.62 & 0.6 & \\
\hline & 3. & 0.9 & 2.5 & 5.3 & 1.76 & 0.48 & $3: 2.4,4: 4.6$ \\
\hline & 2. & 0.7 & 2.5 & 5.6 & 1.96 & 0.81 & $1: 5,2: 2.2$ \\
\hline & $4 .-2$. & 0.6 & 2.5 & 5.6 & 2.0 & 0.83 & \\
\hline
\end{tabular}

Table 2: Collected data of the extended histographic analysis

\begin{tabular}{|l|c|l|c|c|c|c|c|c|c|}
\hline \multicolumn{4}{|c|}{ Topic } & \multicolumn{3}{c|}{ Characteristics of the histogram, ${ }^{\circ} \mathrm{C}$} & \multicolumn{2}{c|}{$\begin{array}{l}\text { Quantitative } \\
\text { factors }\end{array}$} \\
\hline & $\mathrm{a}$ & site & max/min & avg. & med & Sdev & Skew & IE & ES \\
\hline $\begin{array}{l}\text { Windows of wall } \\
\text { No. } 4 \\
t_{\text {env }}=0{ }^{\circ} \mathrm{C}\end{array}$ & 1.0 & around & $15 / 2 / 12.4$ & 13.8 & 13.8 & 0.5 & 0.6 & 0.21 & 0.27 \\
\cline { 2 - 11 } & 0.5 & below & $16.1 / 12.7$ & 13.8 & 13.7 & 0.5 & 0.6 & 0.25 & 0.13 \\
\hline \multicolumn{2}{|l|}{ Wall heating coil, $\mathrm{t}^{\mathrm{amb}}=20^{\circ} \mathrm{C}$} & $53.1 / 23.5$ & 38.2 & 38.5 & 4.8 & 5.5 & 0.73 & - \\
\hline
\end{tabular}




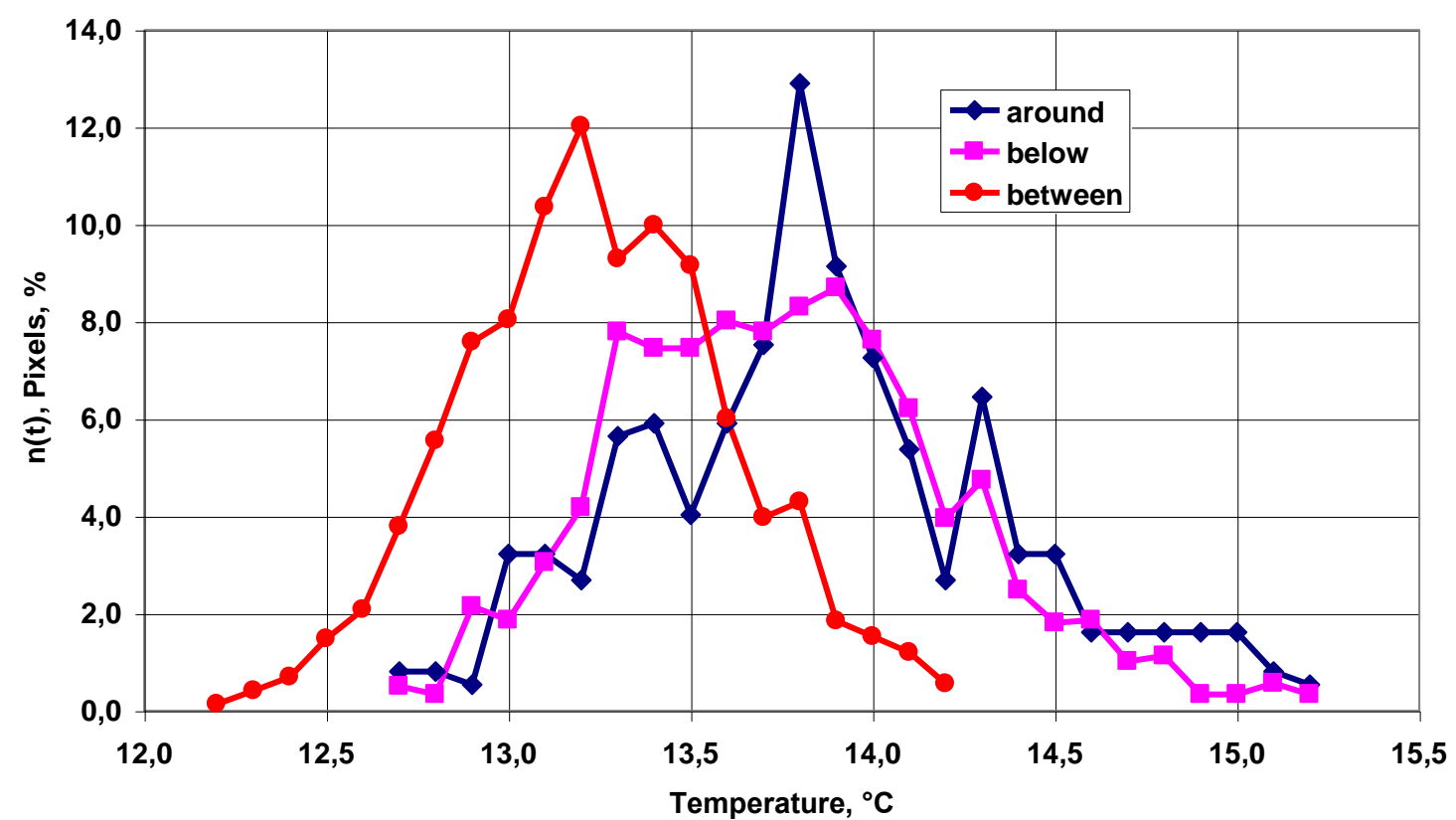

Figure 1: Comparison of the histograms of a building envelope around, below and between the windows

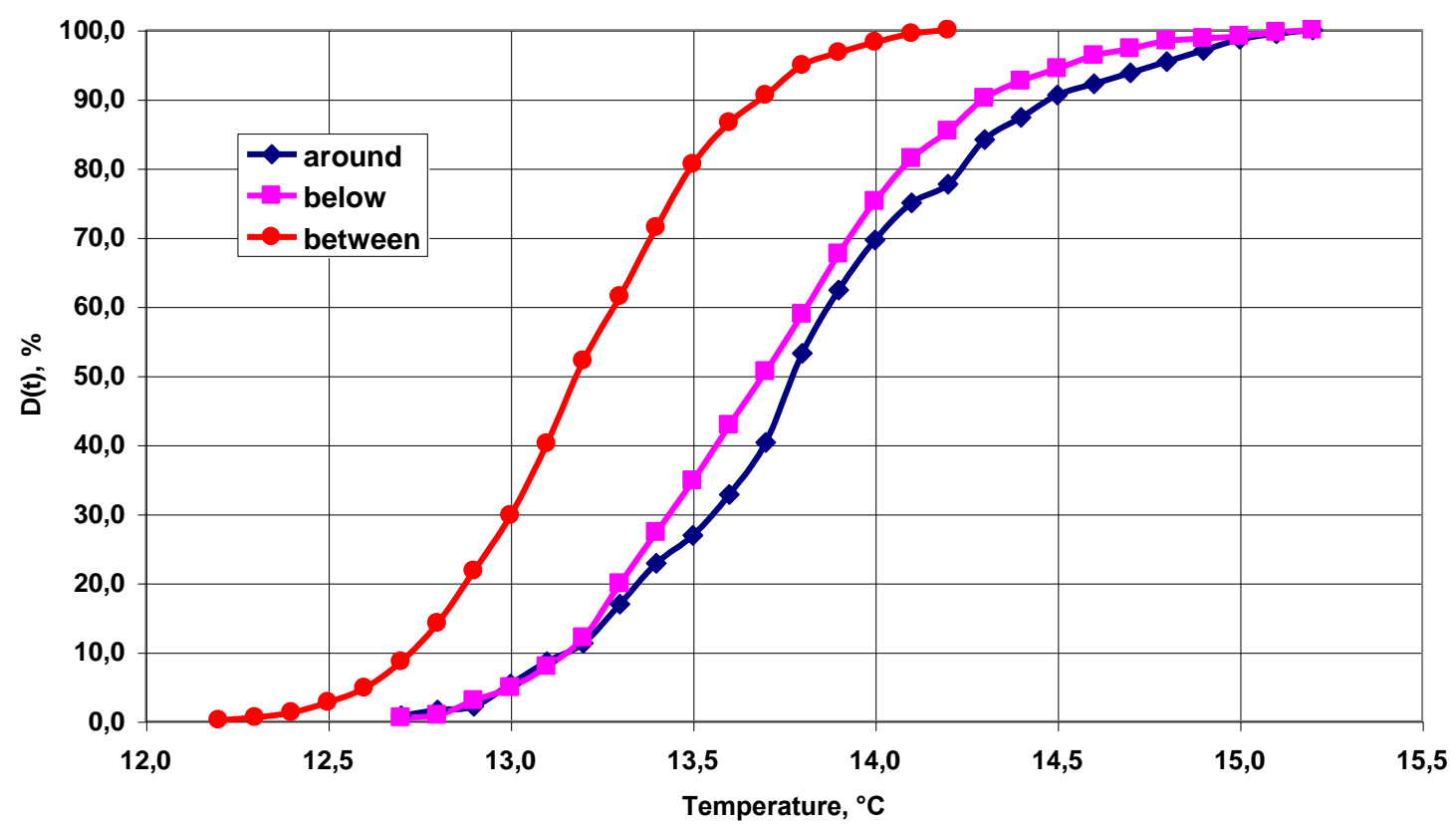

Figure 2: Distributions of histograms of a building envelope around, below and between the windows (see Fig. 1) 
http://dx.doi.org/10.21611/qirt.2000.020

Captions for Figs. 3-5:

Figure 3: Thermogram of an end-walling (No.1, first type) of a building structure oriented to East.

Figure 4: Thermogram of an end-walling (No.2, second type) of the same building structure as on Fig. 3, oriented to West

Figure 5: Histogram of casual and systematic slab faults of an end-walling (No. 3, third type) 